\title{
A STUDY OF THE COMBINATION OF RISK ANALYSIS WITH A CITYWIDE LANDSLIDE EARLY WARNING SYSTEM
}

\author{
JOON-YOUNG PARK ${ }^{1}$, SEUNG-RAE LEE ${ }^{1}$, DEUK-HWAN LEE ${ }^{1}$ \& GOU-MOON CHOI ${ }^{2}$ \\ ${ }^{1}$ Korea Advanced Institute of Science and Technology, Korea \\ ${ }^{2}$ Korea Railroad Research Institute, Korea
}

\begin{abstract}
Due to sharp increase in damages from localized heavy rainfall-induced landslide disasters in Korea since 2000s, there has been increasing interest in researches on the development of effective, practical, and reliable decision-making supportive tools in the disaster management such as early warning systems and risk assessment frameworks. As one of representative outcomes from the researches, a citywide landslide early warning system (LEWS) was developed and implemented in the local government of Busan, the second largest city of Korea, and now under test-operation. With the brief overview on distinctive features of the system, the paper specifically focuses on the concept of debrisflow risk analysis results presented in real-time with the highest warning level, Emergency. Since the areas of Emergency can be theoretically interpreted as debris-flow source areas and they are to be progressively expanded according to the accumulated rainfall input data (e.g., continuous rainfall amount), the initial volume of debris-flow corresponding to a continuous rainfall amount was estimated, and accordingly, numerical simulations and quantitative analyses of debris-flow movements, vulnerabilities and socio-economic properties of risk elements were conducted in the predicted deposition area. A case study was conducted for a vulnerable site to debris-flow in a mountain of Busan. Lastly, thresholds based on human vulnerabilities were introduced and discussed in order to supplement the limitations of risk information based on the building vulnerability.

Keywords: landslide, debris flow, risk analysis, early warning system, threshold.
\end{abstract}

\section{INTRODUCTION}

With the increasing magnitude and number of extreme precipitation events resulting from global climate change, the scale of rainfall-induced landslides and consequent damages have been remarkably enlarged in Korea since the beginning of 21st century. In order to mitigate the increasing landslide disasters and damages, core-technologies are indispensable for the prediction of landslide occurrence, movement, and damages. Therefore, a landslide early warning system capable of deciding five warning levels was developed and now test-operated for Busan, the second largest city in Korea. The citywide regional-scale system, BusanLEWS, uses five different thresholds that are based on various hazard evaluation approaches and determines five-graded early warning levels according to the evaluated landslide imminence at present or 24-hour after the present with the temporal and spatial resolutions of every 10 minutes and $5 \mathrm{~m}$ by $5 \mathrm{~m}$ area, respectively.

With the increasing demands for the quantitative information on properties and live losses from the expected natural disasters, this study tried to analyse the risk of a debris-flow vulnerable site and to incorporate the risk data into Busan-LEWS so that the risk information of specifically important buildings could be provided with in a real-time manner. Additionally, the paper discusses some alternative plans for the evacuation and protection of people by using the human vulnerability indices. 


\section{BUSAN LANDSLIDE EARLY WARNING SYSTEM}

The citywide system (Busan-LEWS) introduced in this paper was developed for the entire Busan area and implemented in the division of disaster management of Busan.

The system consists of five-level warning scheme (Normal, Attention, Watch, Alert, and Emergency) and the five graded warning levels are determined by applying five different thresholds in a step-wise manner, each of which has been defined with different theoretical approach including statistical, physically-based, and numerical analyses as well as a direct measurement. The decision logic of the five warning levels is described in Fig. 1. Firstly, the system collects the real-time hydrological data from the National Weather Service, rainfall observatories distributed in Busan and monitored sites. The other input data including topographic, geological, and geotechnical properties in Busan are established and loaded from Geo-database built in Busan-LEWS. The hydrological and geo-property input data are loaded to the three-step evaluation process at a constant interval time (every 10 minutes for the present and every 6 hours for the forecasting). In the statistical evaluation as the first step, areas of Attention are determined based on three different thresholds which were statistically defined; extreme rainfall-induced landslide index ( $I_{E R L}$ [1]), intensity-duration curve (ID [2]), and a landslide susceptibility index $\left(I_{L S}\right)$ developed for Busan. Since the purpose of the Attention level is in the preliminary warning and preparation, each of the three different statistical thresholds were conservatively defined so as for relatively less intensified rainfalls to call the attentions. Within the area of $I_{L S} \geq 0.1$, the Attention level is assigned if either of the empirically defined rainfall thresholds, $I_{E R L}$ and ID, is exceeded. Then in the physicallybased evaluation step, areas of Watch and Alert are determined within the Attention areas based on a physically and numerically defined threshold in relation to the factor of safety 1.3, named by "continuous rainfall threshold $\left(C R_{F O S=1.3}\right)$ " triggering slope instability. Since "Watch" is theoretically interpreted that $70 \%$ of total continuous rainfall amount triggering the factor of safety less than 1.3 has been accumulated, the level indicates that a little more rainfall will shortly cause drastic increase of slope failure hazard. The slope of "Alert" is interpreted that it has completely reached the slope instability condition. The area of "Alert"

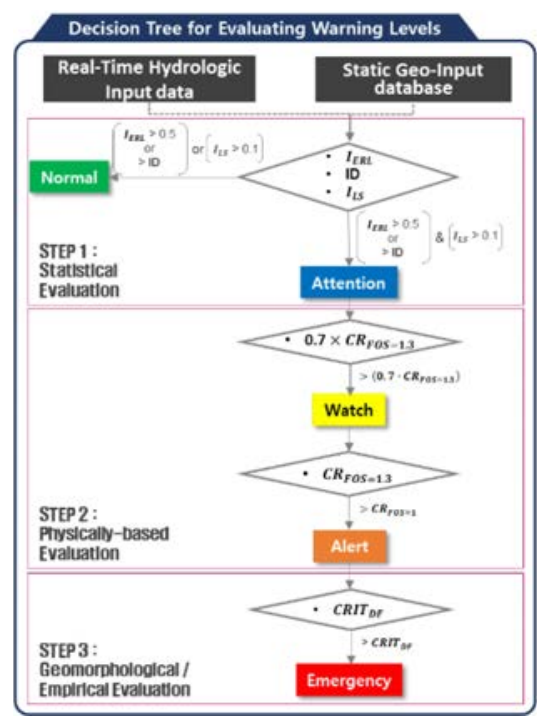

Figure 1: Decision logic for early warning levels of Busan-LEWS. 
is considered as where the soil potentially goes through the shear failure in this study. Finally, in the geomorphological evaluation step, by applying a debris flow mobilization criteria $\left(C R I T_{D F}\right)$ developed by Kang et al. [3], areas where failed soil masses are highly likely mobilized into debris flows are identified within the Alert areas as the highest warning level, Emergency. Park et al. [4] introduces in detail the principles of the system, the methods applied, and the constituting five thresholds with their parameters.

By using the aforementioned decision logic, the system produces an early warning level map as the final output, capable of displaying the early warning levels in the designated colours on a GIS-based interface. The MATLAB program and ArcGIS Model Builder were used to script all the algorithms from the real-time rainfall data processing to the map generation. Fig. 2(a)-(d) show the evolution of early warning levels distributed throughout the Busan mountainous area during the rainfall events that triggered large number of landslides in 2009 as an example of the simulated Busan-LEWS operation. Fig. 2(c) and (d) show that higher landslide early warning levels were determined for the central-southern part of Busan where most landslides occurred, which indicates a generally excellent performance of the model for landslide detection. The unit area of the warning level assignment is $5 \mathrm{~m}$ by $5 \mathrm{~m}$ so as to give detailed warning information for a specific area. Besides, the system runs by two parallel modules; Present and Forecast. The Present module literally determines the landslide early warning levels for the present by mainly using the real-time observed rainfall data. The update interval of the early warning level is 10 minutes. On the other hand, the

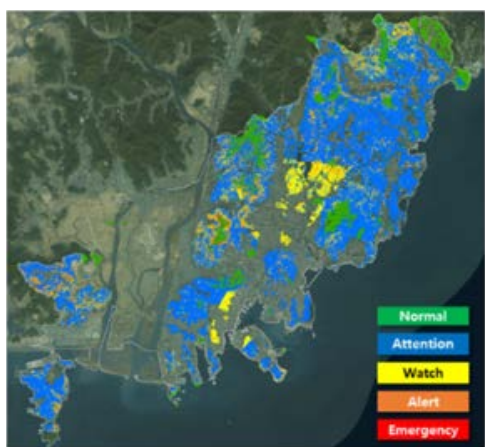

(a)

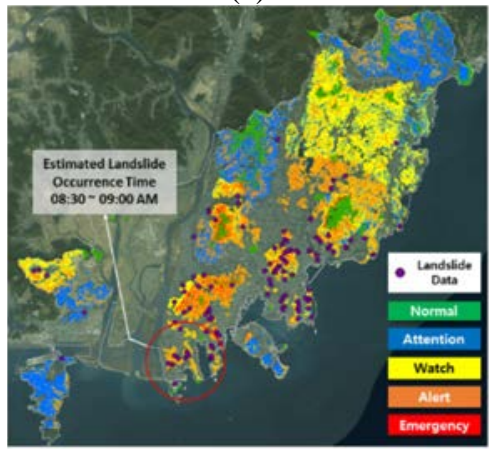

(c)

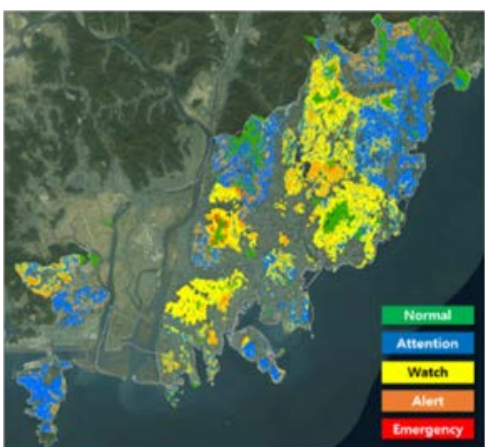

(b)

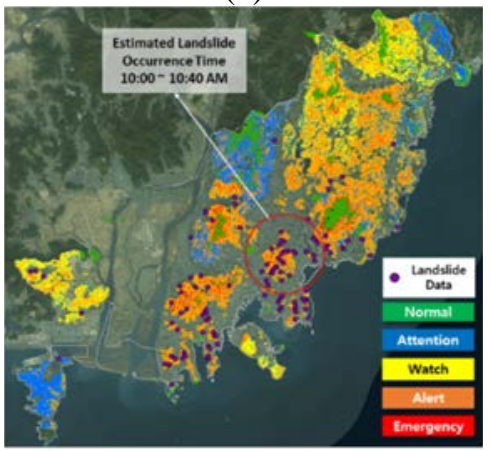

(d)

Figure 2: Evolution of distributed landslide early warning levels for the 2009 landslide event. (a) 06:00 am; (b) 07:00 am; (c) 08:00 am; (d) 09:00 am. (Source: Park et al. [4].) 
Forecast module forecasts the landslide early warning levels for the time after 24 hours by mainly using the forecasted rainfall data. The warning levels are updated every six hours.

\section{CASE STUDY OF RISK ANALYSIS}

In this section, the concept and preliminary results of the risk analysis are reviewed in a sitespecific scale as the initial stage of incorporating risk information into Busan-LEWS. The analysis was conducted to derive and save the building vulnerability and risk (loss of economic values) data of the case study site in order that the risk information and possible guidelines are provided in real-time with the current continuous rainfall amount.

\subsection{Estimation of debris flow sources}

In a predictive debris-flow numerical simulation, initial volume of debris-flow source corresponding to the rainfall characteristics is one of the significant factors. It includes the distribution of source areas and thickness of initially accelerated soil mass. Since the area of the highest warning level (Emergency) is theoretically interpreted as "fully unstable state" and "highly likely to mobilize into debris flow" in Busan-LEWS, it is able to take a role of a potential debris-flow source area. In addition, the source volume can be identified by multiplying the depth of soil mass in "fully unstable state" to the source area since the assumption of shear plane existing at the depth of $1 \mathrm{~m}$ (approximate value of the most prevalent depth of shallow landslides initiated from upper parts of mountainous area in Korea) was applied to the infinite slope stability analyses for deriving the continuous rainfall threshold values.

As shown in Fig. 3, the case study site has features of densified buildings with other structures, and residences at the northwestern foot of a mountain. The analysis was focused on the effects of debris flows originated from the two specific basins as marked in Fig. 3. Fig. 3(a) shows the distribution of continuous rainfall threshold values within the two basins on the area of the debris flow mobilization criteria exceeded, namely the area where the Emergency level other than the Alert level will be assigned when the slope of the area reaches "fully unstable state". Fig. 3(b)-(d) illustrate the evolution of the Emergency areas (redcoloured areas), namely the increasing debris-flow source areas as the continuous rainfall amount increases from $190 \mathrm{~mm}$ to $210 \mathrm{~mm}$. As the warning level map is created as a raster dataset with the resolution of $5 \mathrm{~m}$, the unit grid area is $25 \mathrm{~m}^{2}$. Therefore, the potential debrisflow source volume is able to be calculated by multiplying the grid areas of "Emergency" to the assumed sheared depth $(1 \mathrm{~m})$, with the simplification of soil mass geometry to a cuboid. The debris-flow source volume most sharply increases in the range of continuous rainfall amount between $190 \mathrm{~mm}$ and $210 \mathrm{~mm}$ (Fig. 4). It indicates that the most number of continuous rainfall threshold values on the area are 190, 200, and $210 \mathrm{~mm}$. Each of the analyses including numerical simulation, vulnerability, and risk was conducted as a pilot study for the continuous rainfall amounts of 190, 200, and $210 \mathrm{~mm}$. As one of the cornerstone parameters for the series of analyses, the debris-flow source volumes were calculated for those corresponding continuous rainfall amounts (red and yellow solid circles indicated in Fig. 4).

\subsection{Numerical simulation of debris flow}

Quantifying hazard intensities from a debris flow such as impact pressure, velocity, flow depth, etc. is a paramount work connected to a reliable quantitative assessment of vulnerability and risk. Many of researchers in the history have suggested a variety of models 


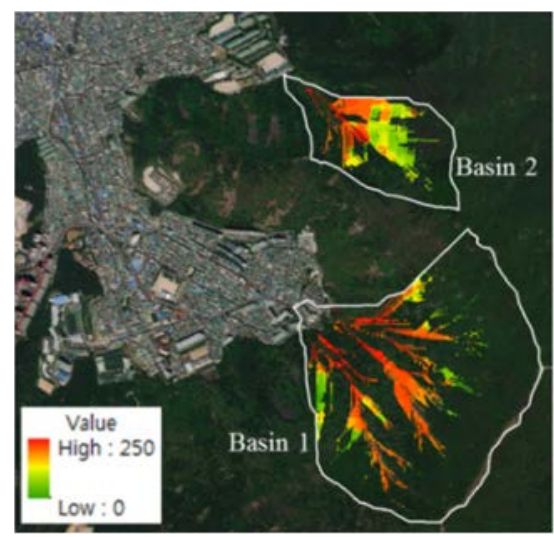

(a)

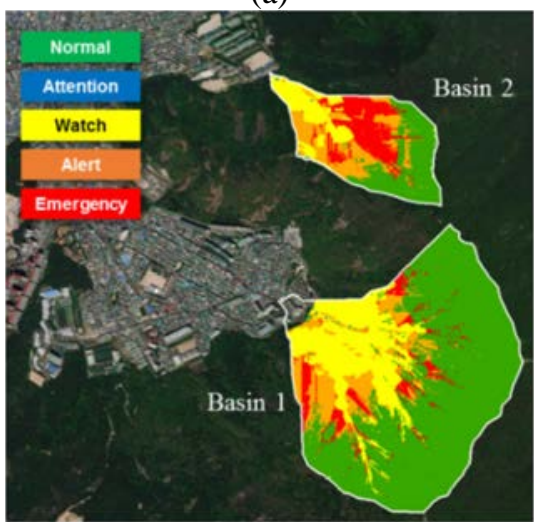

(c)

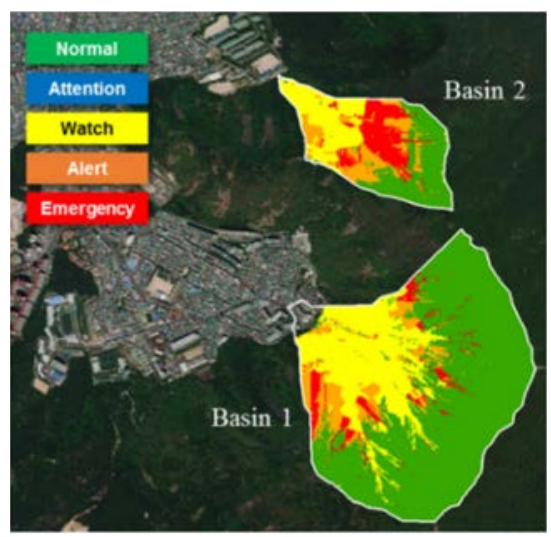

(b)

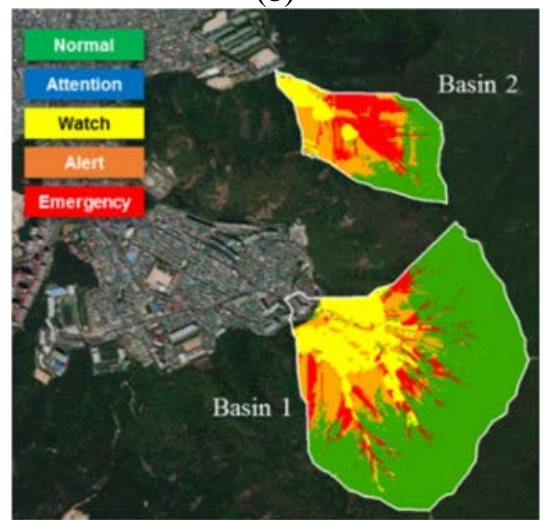

(d)

Figure 3: $\quad$ Basin 1 and 2 in the study site. (a) Distribution of continuous rainfall threshold values; (b) Distributed warning levels in case of $190 \mathrm{~mm}$ continuous rainfall; (c) Distributed warning levels in case of $200 \mathrm{~mm}$ continuous rainfall; (d) Distributed warning levels in case of $210 \mathrm{~mm}$ continuous rainfall.

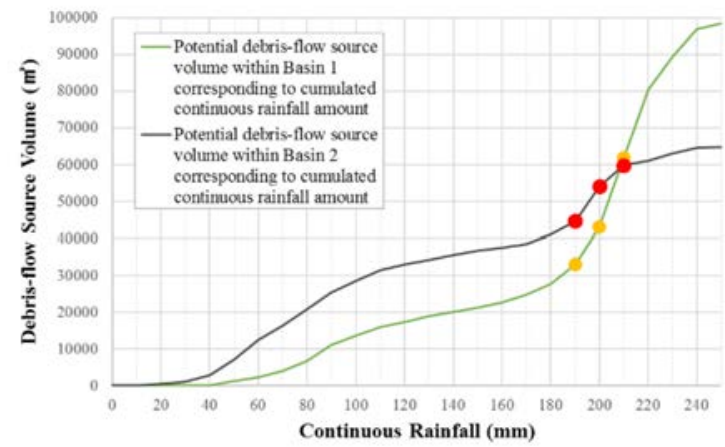

Figure 4: Potential debris-flow source volume corresponding to continuous rainfall amount within Basin 1 and 2. 
to analyze debris flow movement based on either empirical or physically-based approach. In this study, a numerical simulation model, Debris-2D [5] was adopted to analyze the hazard of debris flow. The model, based on the finite difference method, was developed to simulatea number of debris flows composed of fine and coarse materials by using a relationship of shear stress and strain rate proposed by Julien and Lan [6]. As for the set-up of input parameters, the topography data were obtained from digital elevation model (DEM) and the mass source information (volumes and locations) was readily obtained from the results of analysis described in 3.1. The yield stress value was entered as $1,000 \mathrm{dyne} / \mathrm{cm}^{2}$ by referring to the literatures of Debris-2D application studies in Korea for a debris flow hazard simulation [7], [8]. Fig. 5(a)-(c) show examples of analyses results for the depth profiles of propagated debris flows in the case of continuous rainfall of $190 \mathrm{~mm}, 200 \mathrm{~mm}$, and $210 \mathrm{~mm}$, respectively. The effects of a limitation in Debris-2D that it is not able to assess the bed or lateral bank erosion leading to the underestimation of the final volumes was mitigated in the simulation by estimating the initial volume of debris flow with the conservative criterion introduced in 3.1; the factor of safety 1.3 as a criterion determining the shear failure of soil mass and the unified depth of shear plane at $1 \mathrm{~m}$.

\subsection{Vulnerability assessment}

There are several types of elements at risk from debris flow such as structures, population, socio-economic effects, transportation, lifelines, etc. As aforementioned, this study analysed the physical vulnerabilities of buildings by the debris flows potentially expected by continuous rainfall amounts.

According to the debris flow simulation result with the $210 \mathrm{~mm}$ continuous rainfall amount, there were over 1,500 buildings located inside the boundary of debris-flow spread area in the case study site. Since it was unfeasible to draw overall risk amount in the site by conducting the analyses for every single building, five buildings among them were selected for the vulnerability and risk assessment considering the vicinity of hillsides, socio-economic importance, and public accessibility of the building price (Fig. 6).

The impact pressure of debris flow was calculated by an equation including dynamic and static pressure terms, which has been used in many preceding researches [9], [10]. The velocity and depth data at each building were obtained from the debris-flow analysis results and the density of debris flow was assumed $2000 \mathrm{~kg} / \mathrm{m}^{3}$ in reference to the Hu et al. [10] research.

The vulnerability indices for each building shown in Table 1 were derived from a vulnerability curve suggested by Kang and Kim [11] which is a function of the debris flow

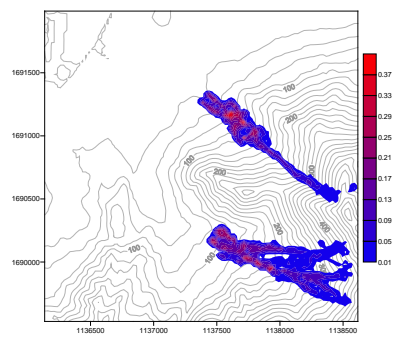

(a)

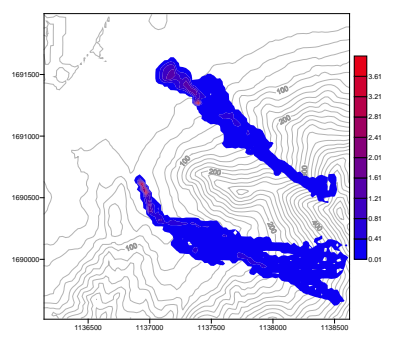

(b)

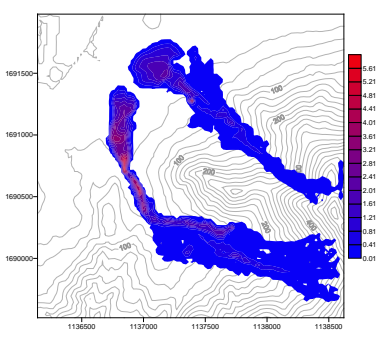

(c)

Figure 5: Numerical analysis of debris flow using Debris-2D. (a) $190 \mathrm{~mm}$ continuous rainfall; (b) $200 \mathrm{~mm}$ continuous rainfall; (c) $210 \mathrm{~mm}$ continuous rainfall. 


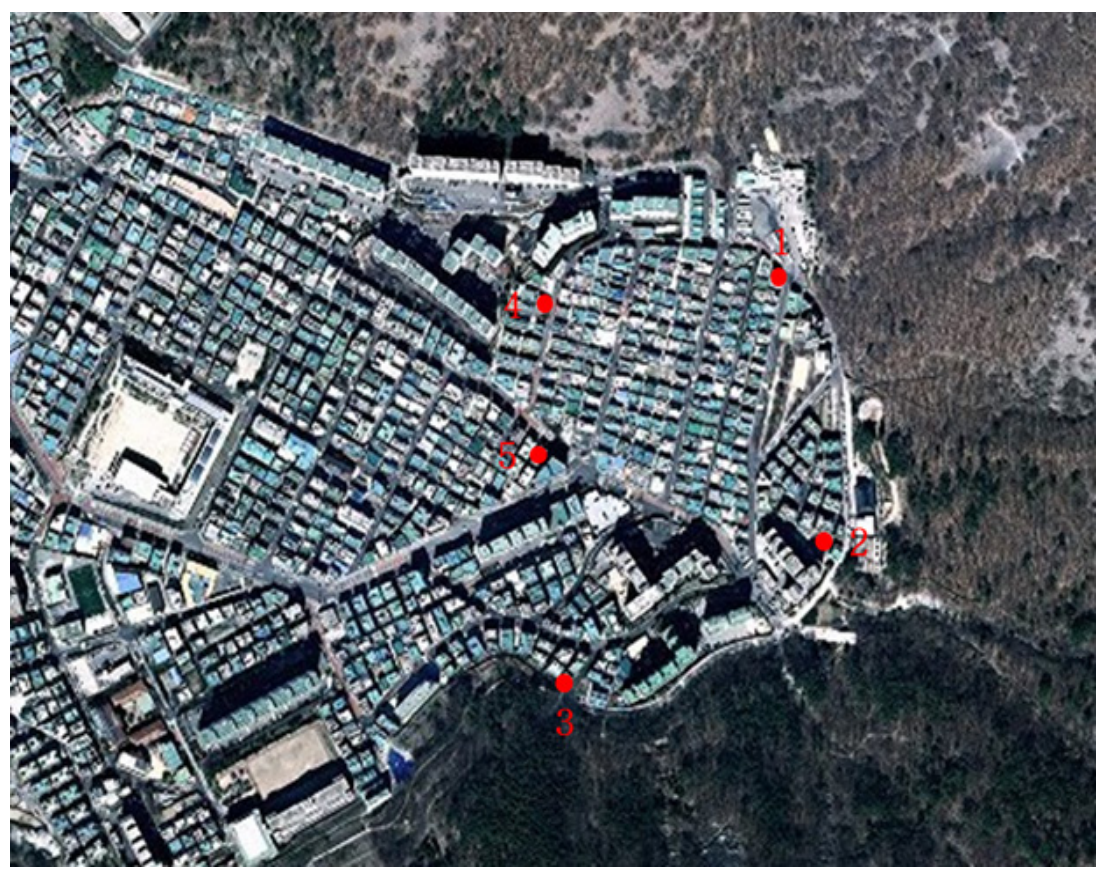

Figure 6: Selection of five buildings for the vulnerability and risk assessment.

Table 1: Vulnerability indices of each building according to the continuous rainfall amount.

\begin{tabular}{|l|l|c|c|c|c|c|}
\hline \multicolumn{1}{|c|}{ Building no. } & 1 & 2 & 3 & 4 & 5 \\
\hline \multirow{4}{*}{$\begin{array}{l}\text { Continuous } \\
\text { rainfall } \\
190 \mathrm{~mm}\end{array}$} & Velocity (m/s) & - & 0.02 & - & 0.01 & 0.025 \\
\cline { 2 - 7 } & Depth (m) & - & 0.05 & - & 0.05 & 0.14 \\
\cline { 2 - 7 } & $\begin{array}{l}\text { Impact pressure } \\
(\text { Pa) }\end{array}$ & - & 490 & - & 490 & 1,373 \\
\cline { 2 - 7 } & Vulnerability & - & 0.009 & - & 0.009 & 0.022 \\
\hline \multirow{4}{*}{$\begin{array}{l}\text { Continuous } \\
\text { rainfall } \\
200 \text { mm }\end{array}$} & Velocity (m/s) & 0.02 & 0.04 & - & 0.03 & 0.05 \\
\cline { 2 - 7 } & Depth (m) & 0.1 & 0.3 & - & 0.15 & 0.5 \\
\cline { 2 - 7 } & $\begin{array}{l}\text { Impact pressure } \\
(\text { Pa) }\end{array}$ & 981 & 2,943 & - & 1,472 & 4,905 \\
\cline { 2 - 7 } & Vulnerability & 0.016 & 0.044 & - & 0.024 & 0.069 \\
\hline \multirow{3}{*}{$\begin{array}{l}\text { Continuous } \\
\text { rainfall } \\
210 \text { mm }\end{array}$} & Velocity (m/s) & 0.03 & 0.06 & - & 0.045 & 0.1 \\
\cline { 2 - 7 } & Depth (m) & 0.15 & 0.4 & - & 0.3 & 1 \\
\cline { 2 - 7 } & $\begin{array}{l}\text { Impact pressure } \\
\text { (Pa) }\end{array}$ & 1,472 & 3,927 & - & 2,944 & 9820 \\
\cline { 2 - 7 } & Vulnerability & 0.024 & 0.057 & - & 0.044 & 0.127 \\
\hline
\end{tabular}


impact pressure for different structural types of buildings. The structural types of five buildings have all the reinforced-concrete (RC) frame, and then the vulnerability curve for the RC building was applied in this study. The curves have been determined by observing the relationship between the degree of building damage and the intensity of the debris flow events in Korea.

\subsection{Risk assessment}

The concept of risk assessment is to describe the expected potential damage amount from a hazard as economic values and the values in this study were drawn by the vulnerability indices multiplied by the publicly notified building prices (currency unit: South Korean won, KRW) of the five buildings (Table 2). The building price data were able to be obtained in a website uploading real-estate information provided by the Korea government. As a result, the database of the risk information corresponding to the continuous rainfall amounts has been established. With the risk information data additionally accumulated for other continuous rainfall amounts and incorporated into Busan-LEWS, it is expected that owners or stakeholders of the five buildings will be provided with the information about monetary damages and rehabilitation costs regarding the real-time continuous rainfall amounts observed.

\section{DISCUSSION}

It should be noted that although the potentially unstable initial volumes in the range of relatively small amounts of continuous rainfall $(0-80 \mathrm{~mm})$ were technically able to be obtained as plotted in Fig. 4 by using the raster dataset of the continuous rainfall thresholds, it was unnecessary to conduct the risk and vulnerability assessment since most of area in the basins kept the "Normal" or "Attention" level in the early warning simulation until the

Table 2: Risk assessment results for buildings according to the continuous rainfall amount.

\begin{tabular}{|c|c|c|c|c|c|}
\hline $\begin{array}{l}\text { Building } \\
\text { type }\end{array}$ & $\begin{array}{c}\text { Building } \\
\text { no. }\end{array}$ & $\begin{array}{l}\text { Continuous } \\
\text { rainfall (mm) }\end{array}$ & $\begin{array}{l}\text { Building } \\
\text { price } \\
(\mathrm{KRW})\end{array}$ & Vulnerability & Risk (KRW) \\
\hline \multirow{15}{*}{$\begin{array}{l}\text { Reinforced- } \\
\text { concrete } \\
\text { frame }\end{array}$} & \multirow{3}{*}{1} & 190 & \multirow{3}{*}{$44,000,000$} & - & - \\
\hline & & 200 & & 0.016 & 715,963 \\
\hline & & 210 & & 0.024 & $1,034,970$ \\
\hline & \multirow{3}{*}{2} & 190 & \multirow{3}{*}{$235,000,000$} & 0.009 & $2,033,172$ \\
\hline & & 200 & & 0.044 & $10,326,906$ \\
\hline & & 210 & & 0.057 & $13,363,111$ \\
\hline & \multirow{3}{*}{3} & 190 & \multirow{3}{*}{$52,000,000$} & - & - \\
\hline & & 200 & & - & - \\
\hline & & 210 & & - & - \\
\hline & \multirow{3}{*}{4} & 190 & \multirow{3}{*}{$159,000,000$} & 0.009 & $1,374,995$ \\
\hline & & 200 & & 0.024 & $3,740,007$ \\
\hline & & 210 & & 0.044 & $6,988,950$ \\
\hline & \multirow{3}{*}{5} & 190 & \multirow{3}{*}{$57,000,000$} & 0.022 & $1,259,117$ \\
\hline & & 200 & & 0.069 & $3,948,323$ \\
\hline & & 210 & & 0.127 & $7,231,532$ \\
\hline
\end{tabular}


continuous rainfall accumulates over about $80 \mathrm{~mm}$, which is theoretically interpreted as "some artificial slope's failure possibly occur" and "very unlikely for a naturally-induced landslide or a debris-flow to occur".

An early warning system takes as an ultimate purpose "the instant and relevant actions against an imminent hazard to mitigate human life damage and evacuate people". The concept of risk information (economic values) of buildings provided corresponding to the real-time observed continuous rainfall amount at a debris-flow vulnerable site has a limitation in the sense that it may not be the optimal type of information from the early warning perspective. In addition, it is difficult for the suggested concept to analyse the total risk of a site from a single or multiple debris flows in case that too many buildings are located within the boundary of debris-flow spread area.

In order to supplement the limitations of the suggested concept, an approach to set up a threshold that might trigger injuries or deaths of residents may be necessary to be applied into the real-time Busan-LEWS. As a further study, Fig. 7(a) and (b) represent two separate approaches to set up a threshold for the people inside buildings and for the people in open spaces, respectively. By referring to [12], it was deduced that there exists high chance of injuries and deaths from the building vulnerability of 0.8 . The buildings that turned red at the 210mm continuous rainfall amount in Fig. 7(a) are the ones that exceeded the vulnerability of 0.8 and that are required to evacuate people. On the other hand, according to Wong and Ko [13] studies on the chance of death and escape for individuals by overland flow, the damage on pedestrians are expected on the area where the depth of debris-flow is higher than $0.4 \mathrm{~m}$. The yellow and red dotted lines in Fig. 7(b) are the boundaries of restricted areas for pedestrians and vehicles determined by the criterion of the $0.4 \mathrm{~m}$ depth from the debris-flow simulation results for 190, 200, and $210 \mathrm{~mm}$, respectively.

When the database for the human vulnerability analyses as preliminarily introduced in Fig. 7 is completely set up for all of the debris-flow vulnerable sites and incorporated into BusanLEWS, the system is expected to serve as an integrated and advanced decision-making supportive tool from the early warning stage to the stage of evacuation and management of risk areas.

\section{CONCLUSION}

This paper summarizes a study trying to incorporate the physical vulnerability and risk assessment results of some specific buildings into a real-time landslide early warning system. The initial volumes of potential debris flows were able to be identified based on the areas assigned with the Emergency level from Busan-LEWS. By completing the set-up of the database of the risk and vulnerability indices for other continuous rainfall amounts between 90 and $250 \mathrm{~mm}$, the real-time risk information for some buildings of special interest is expected to be disseminated from Busan-LEWS. This information will support management of risk areas, prioritization of national disaster management policies, and future construction planning. However, as discussed in the previous section, the optimal and truly completed landslide early warning system will be required to incorporate not only the risk information of important and vulnerable buildings but also the thresholds that provide with critical rationale for evacuation and instant counteractions to protect human life based on the results of human vulnerability analyses. With the several years of test-operation and improvement in Busan, the advanced and integrated landslide early warning system suggested in this paper is expected to be extended to nationwide in Korea as a future prospect. 


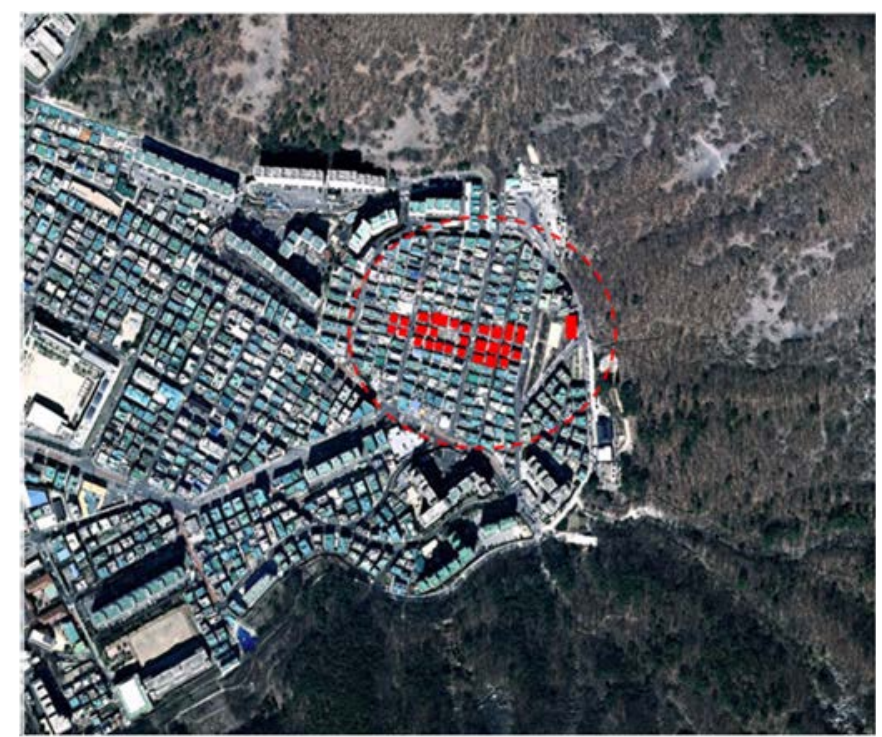

(a)

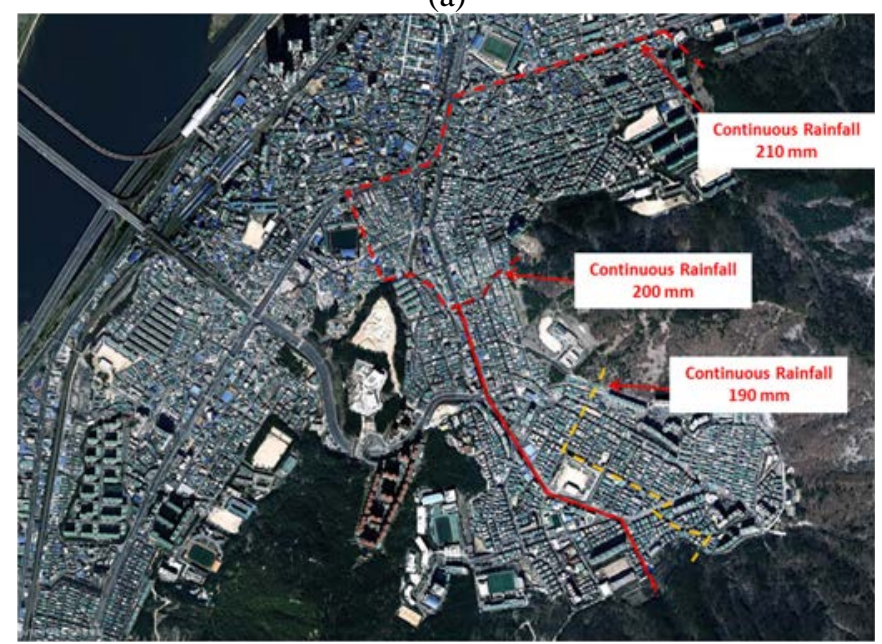

(b)

Figure 7: Preliminary analyses for the human vulnerability. (a) Buildings for evacuation at $210 \mathrm{~mm}$ continuous rainfall; (b) Boundaries of the restricted area for pedestrians and vehicles.

\section{ACKNOWLEDGEMENTS}

The present work was supported by the Public Welfare \& Safety Research Program through the National Research Foundation of Korea (NRF) funded by the Ministry of Science and ICT (NRF2012M3A2A1050974), the U-City Master and Doctor Course Grant Program funded by the Korea Ministry of Land, Infrastructure and Transport (MOLIT), and the Technology Advancement Research Program (TARP) (18CTAP-C143742-01) by Ministry of Land, Infrastructure and Transport of Korean government. 


\section{REFERENCES}

[1] Vasu, N.N., Lee, S.R., Pradhan, A.M.S., Kim, Y.T., Kang, S.H. \& Lee, D.H., A new approach to temporal modelling for landslide hazard assessment using an extreme rainfall induced-landslide index. Engineering Geology, 215, pp. 36-49, 2016.

[2] Kang, H.S. \& Kim, Y.T., A study on warning level-based-landslide triggering rainfall criteria considering weathered soil type and landslide type. Journal of the Korean Society of Hazard Mitigation, 16(2), pp. 341-350, 2016.

[3] Kang, S., Lee, S.R., Nikhil, N.V., Park, J.Y. \& Lee, D.H., Development of an initiation criterion for debris flows based on local topographic properties and applicability assessment at a regional scale. Engineering Geology, 230, pp. 64-76, 2017.

[4] Park, J.Y., Lee, S.R., Lee, D.H., Kim, Y.T., Oh, S. \& Park, H.J., Development of continuous rainfall-based citywide landslide early warning model. J. Korean Soc. Hazard Mitig., 18(1), pp. 99-111, 2018.

[5] Liu, K.F. \& Huang, M.C., Numerical simulation of debris flow with application on hazard area mapping. Computational Geosciences, 10, pp. 221-240, 2006.

[6] Julien, P.Y. \& Lan, Y., Rheology of hyper concentrations. Journal of Hydr. Engrg., ASCE, 117, pp. 346-353, 1991.

[7] Chae, B.G., Liu, K.F. \& Kim, M.I., A case study for simulation of a debris flow with DEBRIS-2D at Inje, Korea. The Journal of Engineering Geology, 20(3), pp. 231-242, 2010.

[8] Liu, K.F. \& Wu, Y.H., The assessment of debris flow hazard in Korea using Debris2D. INTERPRAEVENT 2010 - International Symposium in Pacific Rim, Taipei, Taiwan, 2010.

[9] Zanchetta, G., Sulpizio, R., Pareschi, M.T., Leoni, F.M. \& Santacroce, R., Characteristics of May 5-6, 1998 volcaniclastic debris-flows in the Sarno area of Campania, southern Italy: relationships to structural damage and hazard zonation. J. Volcanol. Geoth. Res., 133, pp. 377-393, 2004.

[10] Hu, K.H., Cui, P. \& Zhang, J.Q., Characteristics of damage to buildings by debris flows on 7 August 2010 in Zhouqu, western China. Nat. Hazards Earth Syst. Sci., 12, pp. 2209-2217, 2012.

[11] Kang, H.S. \& Kim, Y.T., Study on physical vulnerability curves of buildings by numerical simulation of debris flow. Journal of Korean Society of Hazard Mitigation, 15(5), pp. 155-167, 2015.

[12] Finlay, P.J., Mostyn, G.R. \& Fell, R., Landslide risk assessment: prediction of travel distance. Canadian Geotechnical Journal, 36(3), pp. 556-562, 1999.

[13] Wong, H.N. \& Ko, F.W.Y., Quantitative Risk Assessment of Landslide Hazards at Fu Yung Shan Tsuen, Tsuen Wan, Geotechnical Engineering Office, Civil Engineering and Development Department, 2008. 